\title{
Physiological stress assessment of female workers at kitchen workstation
}

\author{
Hema Bhatt ${ }^{\mathrm{a}}$ and M K Sidhu ${ }^{\mathrm{b}}$ \\ ${ }^{a}$ Department of Family Resource Management, G.B. Pant University of Agriculture \& Technology, Pantnagar, \\ Uttarakhand; e-mail: hemabhatt2000@gmail.com \\ ${ }^{b}$ Department of Family Resource Management, Department of Family Resource Management, Punjab \\ Agricultural University, Ludhiana,Punjab; e-mail: muninderkaur@pau.edu,
}

\begin{abstract}
This paper explores the extent of the physiological stresses of female workers at kitchen workstation while performing the various activities. For this a survey of eighty homemakers and experiment on sixteen respondents having similar physical and physiological parameters was done. Five activities in which the respondents faced maximum problems were selected and were standardized. Physiological stresses including cardiovascular, muscular, and energy expenditure during these activities were then assessed. Study revealed that fatigue during the selected five activities i.e. cutting, grating, rolling, kneading, dish washing, was felt mainly at the wrist, fore arm, followed by discomfort in the shoulders, upper arm, lower back and neck. Energy expenditure for these activities ranged from 7.0 to10 kJ $\backslash$ min, total cardiac cost of work (TCCW) was between 200.81 to 364.30 beats, physiological cost of work (PCW) was 12.82 to 26.26 beats $\backslash$ min; maximum for grating and minimum for rolling. The percent increase in heart rate was maximum for grating 38.56 and minimum for rolling 16.20 . Reduction in grip and pinch strength of right hand was found more as compared to the left hand.
\end{abstract}

Keywords: Ergonomics, Physiological stress, Cooking activities, Energy expenditure, Workstation

\section{Introduction}

Use of ergonomic science in disposing of the day to day work load of housewife has been found important these days because there is an increased demand on the available resources of women who perform dual type of work both inside and outside the home. Being the most important room in a house, environment of the kitchen should be highly conducive when performing daily kitchen activities. A well planned and designed kitchen is that which provides all the requirement of the work, worker and workplace with special reference to arrangement and dimension of work areas, storage space and placement of equipment in the way that can reduce the temporal and physical efforts of the homemaker and may provide the basis for a satisfactory working environment. Kitchen workstation is a complex system, wherein man interacts with many machines simultaneously and in parallel with the environment that is dynamic. Conducive environment is crucial to anyone in performing day to day routine activities especially for the homemaker or the worker involved in different activities. Any work station design or work environment that helps to perform the work with minimum energy and put minimum stress on cardio vascular system and muscular system is the best design of work (Varghese et al, 1995)[6]. So the kitchen workstation should be adequately designed and properly arranged in order to reduce the physical, physiological and temporal costs of the homemaker.

\section{Method}

Present study was conducted in Ludhiana state. For study five activities in which the respondents faced maximum problems were selected through a survey of eighty homemakers. These were cutting, kneading, rolling, grating and dish washing. Sixteen respondents having similar physical and physiological parameters were selected for experimentation to know the physiological stresses while performing these activities. Besides this information was gathered regarding the fatigue felt by the respondents at the various body parts during different activities. 


\subsection{Equipment used and assessment of physiological parameters}

Equipment like polar heart rate monitor, grip dynamometer, pinch dynamometer were used to record the data related to their heart rate, grip strength, and pinch strength.

Based on the heart rate records the following parameters were calculated:

1. Average heart rate during rest, work and recovery period.

2. The energy expenditure per minute was estimated from heart rate using the following formula and the classification of work load was done as per Varghese et al (1994)[7]: Energy Expenditure (k $\mathrm{J} / \mathrm{min}$ ) $=0.159 \times$ Average Heart rate (beats $/ \mathrm{min}$ ) 8.72

3. The Total Cardiac Cost of Work (TCCW) was also estimated for the whole day based on the cardiac cost of work and cardiac cost of recovery: Cardiac Cost of Work $(\mathrm{CCW})=$ Increased Average heart rate $\mathrm{x}$ Duration of work; Increased Average heart rate during work $=$ Average working heart rate - Average heart rate during Rest; Cardiac Cost of Recovery $(\mathrm{CCR})=$ Increased average heart rate during recovery x Duration; Increased Average heart rate during recovery $=$ Average Recovery heart rate Average resting heart rate

\subsection{Statistical analysis of experimental data}

The data collected were tabulated and suitable statistical tool such as averages, percentages, correlation coefficient, standard deviation and paired ' $t$ ' test were used for analysis of data.

\section{Results}

\subsection{Fatigue reported while performing activities}

The information regarding the number of respondents feeling fatigue in different activities and the various body parts where the fatigue is felt is presented in fig 1 and 2 . It depicts that the maximum respondents felt fatigue, while performing activities like grating (40.00 per cent), kneading (38.75 per cent), dish-washing (37.50 per cent) and rolling chapattis (33.75 per cent). Minimum number of respondents complained fatigue while performing activities like puffing chapattis (8.75 per cent), stirring (12.50 per cent) and sieving (21.25 per cent).
While performing the above mentioned kitchen activities fatigue was felt by the homemakers forearm and wrist. During these activities trouble spots disclosed were mainly the wrist, fore arm, followed by discomfort in the shoulders, upper arm, lower back and neck.

These findings are in line with those reported by the Jindal (2000)[2] who also found out that homemakers felt tiredness and pain in arms, back and legs after performing the kitchen work. The reason for this may be due to the more height of the work counter along with hard activity where force has to be applied. Sandhu et al (2008)[5] reported that one-fourth of women felt pain after working for long hours at the counter. More significantly, many women across height groups reported stress in the legs from a counter that is too high for kneading and cooking.

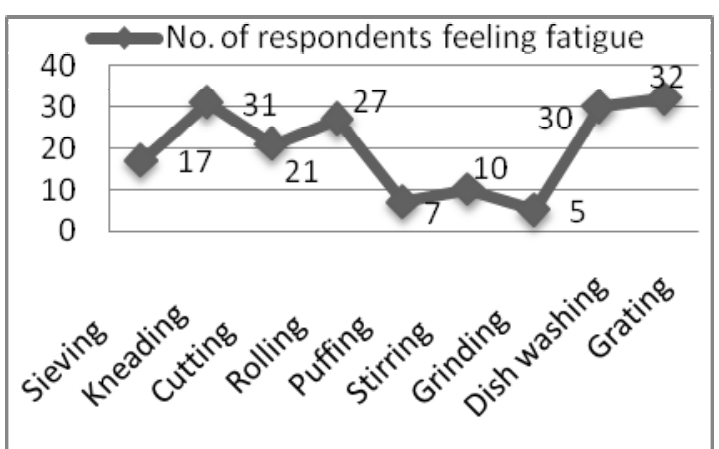

Fig. 1 Distribution of respondents according to fatigue experienced while performing selected activities

\subsection{Cardiovascular responses during the selected activities}

Table 1 gives the information that while performing different activities in the kitchen average heart rate was found to be maximum during grating (106 beats/min) and minimum during rolling (91beats/min). Increase over base in average heart rate was also maximum for grating (29.5) and minimum for rolling (13.1). It was observed that percent increase of heart beat was 38.56 for grating, 34.74 for kneading, 30.57 for cutting, 21.29 for dish washing and only 16.2 for rolling of chapatti. So it can be concluded that among the selected kitchen activities maximum force was exerted for grating followed by kneading dough. The least force was required for rolling chapattis. The paired ' $\mathrm{t}$ ' test results were found to be highly significant at $1 \%$ level of significance indicating that there is 
significant difference in the average heart rate at rest and during activity

\subsection{Energy Expenditure, Total Cardiac Cost of Work (TCCW) and Physiological Cost of Work $(P C W)$ of different activities}

Amongst the selected activities the mean values for energy expenditure, total cardiac cost of work (TCCW) and physiological cost of work (PCW) are depicted in fig 3, 4 and 5 . These were found to be maximum for grating $(10.00 \mathrm{~kJ} \backslash \mathrm{min}, 364$ beats and 26.26 beats $\backslash$ min respectively), followed by kneading (9.40 $\mathrm{kJ} \backslash \mathrm{min}, 241$ beats and 18.43 beats $\backslash \mathrm{min}$ respectively), cutting ( $9.06 \mathrm{~kJ} \backslash \mathrm{min}, 216$ beats and 15.32 beats $\backslash \mathrm{min})$, dish washing $(7.30 \mathrm{~kJ} \backslash \mathrm{min}, 213$ beats and 13.98 beats $\backslash \mathrm{min}$ ) and minimum in rolling (7.00kJ $\backslash \mathrm{min}, 201$ beats and 13.98 beats $\backslash \mathrm{min})$. So, according to the workload classification given by Varghese et. al.(1994)[7] the physiological workload of the activities can be interpreted as light activity for rolling and dish washing,

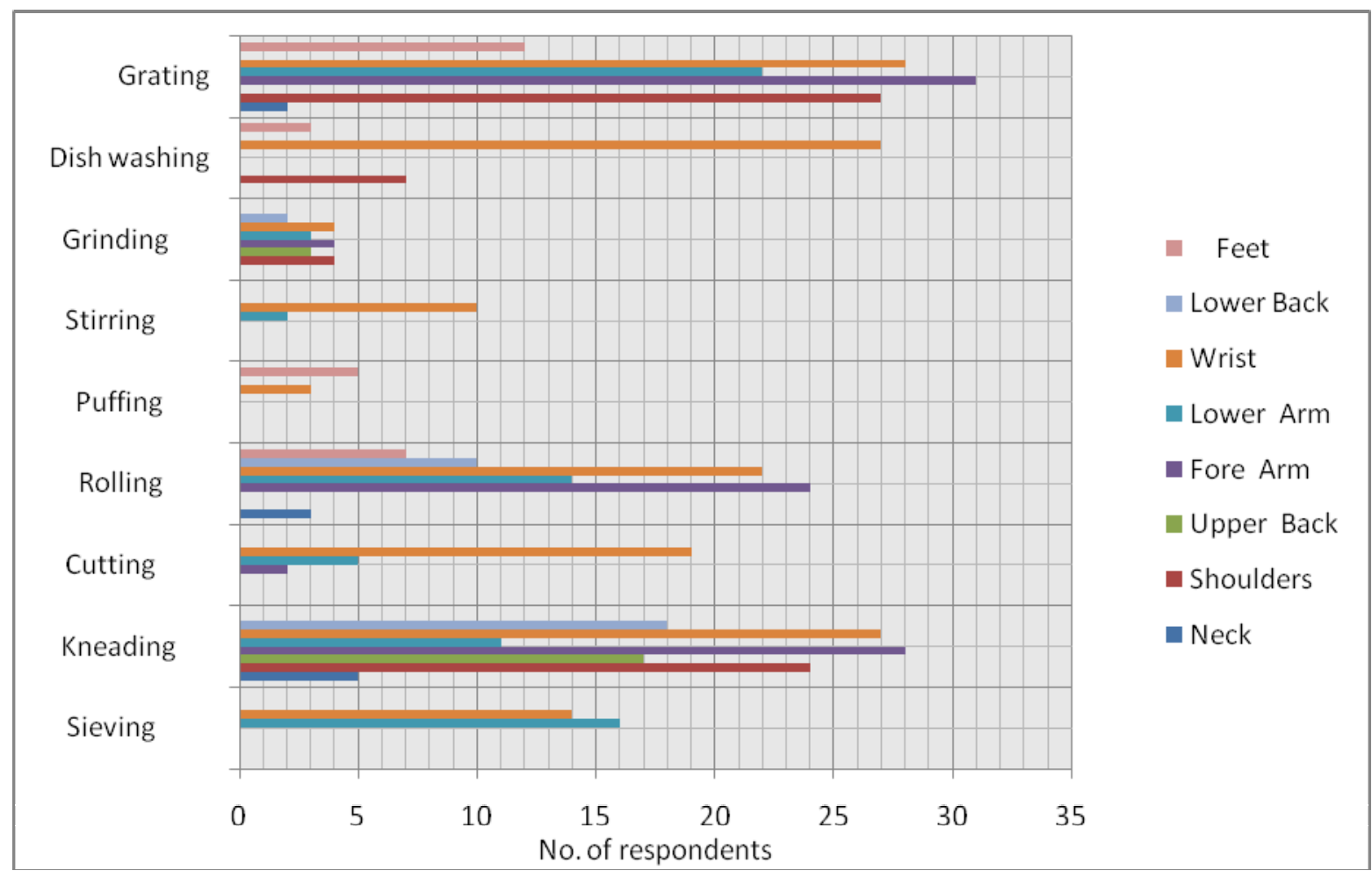

Fig. 2 Fatigue realization in different body parts while performing activity

Table 1.

Increase in cardiovascular responses of the selected respondents while performing the different activities 


\begin{tabular}{|c|c|c|c|c|c|}
\hline Activity & $\begin{array}{l}\text { At rest } \\
\text { (beats } \backslash \text { min) }\end{array}$ & $\begin{array}{l}\text { During activity } \\
\text { (beats } \backslash \text { min) }\end{array}$ & $\begin{array}{l}\text { Increase } \\
\text { over base }\end{array}$ & $\begin{array}{l}\text { Percentage } \\
\text { Increase }\end{array}$ & 't' value \\
\hline Cutting & $\begin{array}{c}76.20 \\
+0.84\end{array}$ & $\begin{array}{l}99.5 \\
\pm 2.75\end{array}$ & 23.3 & $\begin{array}{l}30.57 \\
\pm 3.7\end{array}$ & $47.65^{*}$ \\
\hline Grating & $\begin{array}{l}76.50 \\
\pm 0.97\end{array}$ & $\begin{array}{l}106 \\
\pm 5.0\end{array}$ & 29.5 & $\begin{array}{l}38.56 \\
\pm 2.5\end{array}$ & $44.18^{*}$ \\
\hline Kneading & $\begin{array}{l}77.70 \\
\pm 0.83\end{array}$ & $\begin{array}{l}104.7 \\
\pm 4.40\end{array}$ & 27 & $\begin{array}{l}34.74 \\
\pm 4.6\end{array}$ & $60.37 *$ \\
\hline Rolling & $\begin{array}{l}77.90 \\
\pm 1.87\end{array}$ & $\begin{array}{l}91 \\
\pm 2.56\end{array}$ & 13.1 & $\begin{array}{l}16.2 \\
\pm 5.2\end{array}$ & $20.03 *$ \\
\hline Dish washing & $\begin{array}{l}77.50 \\
\pm 0.93\end{array}$ & $\begin{array}{l}94 \\
\pm 3.22\end{array}$ & 16.5 & $\begin{array}{l}21.29 \\
\pm 3.5\end{array}$ & $26.32 *$ \\
\hline
\end{tabular}

whereas moderately heavy for cutting, kneading and grating. These findings are similar to Landan and Stubler (1999) [3] who found that energy expenditure for cooking was estimated to be 7.2$12.2 \mathrm{~kJ} \backslash \mathrm{min}$., and particularly for kneading 10.8 $\mathrm{kJ} \backslash \min$.

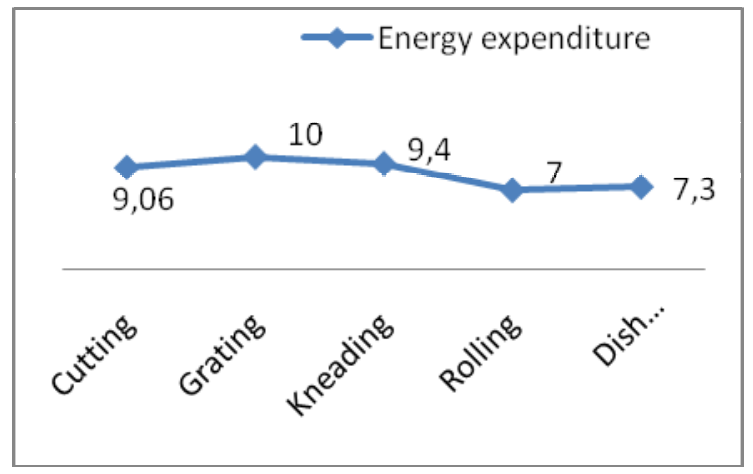

Fig 3 Energy expenditure $(\mathrm{kJ} / \mathrm{min})$ after performing various activities

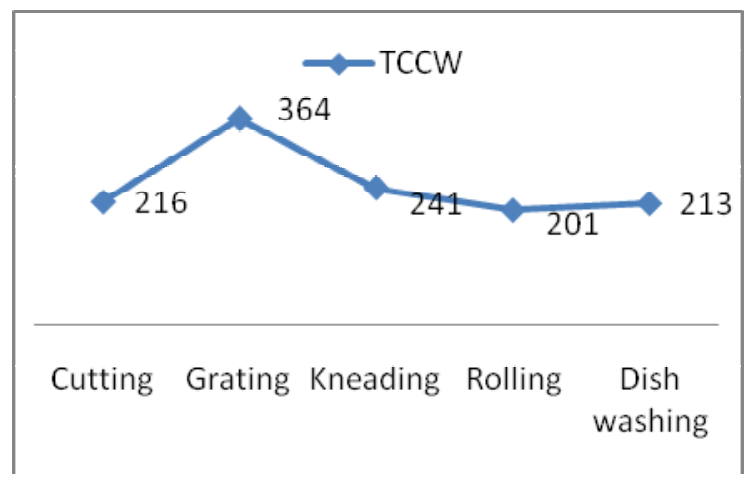

Fig 4 Total Cardiac Cost of Work (beats) after performing various activities



Fig 5 Physiological Cost of Work (beats/min) after performing various activities

\subsection{Muscular stress of selected subjects}

Muscular stress was assessed by measuring the reduction in larger and smaller muscles of hand by using the grip and pinch dynamometer.

3.4.1 Reduction in muscular grip strength (Kg) of selected subjects in doing selected activities

The mean values of percentage decrease of the muscular strength for both the hands independently (right hand, left hand) are presented in Fig. 6. It indicates that the maximum percentage reduction in both the hands occurred while kneading (28.89\% and $29 \%$ for left and right hand respectively) and minimum was observed after the activity of rolling $(12.85 \%$ and $13.33 \%$ for left and right hand respectively).

Further the data also indicate that the percent decrease in grip strength of right hand was more as compared to left hand. The paired ' $t$ ' test values were found to be comparatively more significant for right hand (1\% level of significance). Armstrong and Oldham (1999) [1] suggested that dominant hand (right hand) is about $10 \%$ stronger than non- 
dominant hand (left hand). This may be due to more habitual use of right hand for doing activities by all the subjects as compared to left hand.

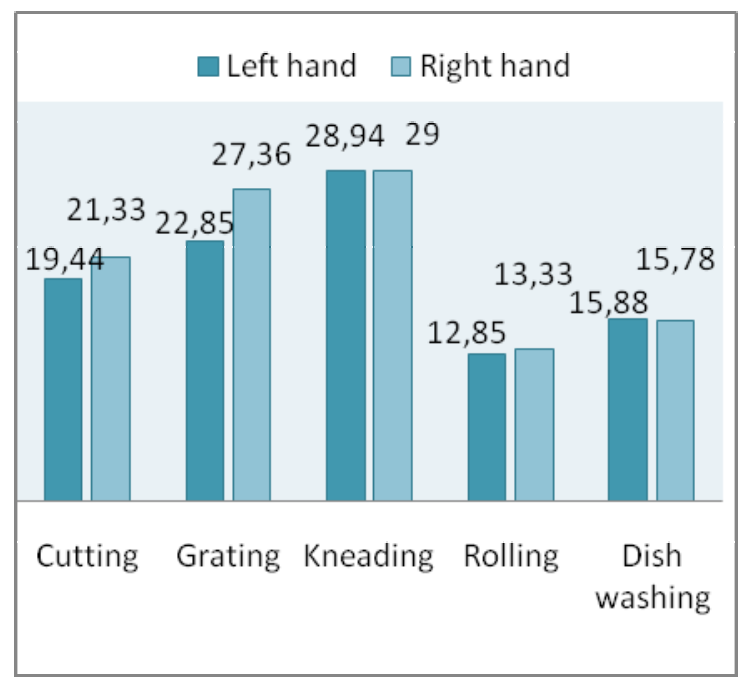

Fig. 6 Percentage reduction in the grip strength of left and right hand after performing the selected activities.

Table 2.

Reduction in muscular pinch strength $(\mathrm{Kg})$ of selected subjects in doing selected activities.

\begin{tabular}{|c|c|c|c|c|c|c|c|c|c|c|}
\hline \multirow{2}{*}{ Activity } & \multicolumn{4}{|c|}{ Left Hand (Kg) } & \multicolumn{6}{|c|}{ Right Hand (Kg) } \\
\hline & $\begin{array}{l}\text { Before } \\
\text { activit } \\
\mathbf{y}\end{array}$ & $\begin{array}{l}\text { After } \\
\text { activity }\end{array}$ & $\begin{array}{l}\text { Decrease } \\
\text { over base }\end{array}$ & $\begin{array}{c}\% \\
\text { Reduction }\end{array}$ & $\begin{array}{c}\text { 't' } \\
\text { Value* }\end{array}$ & $\begin{array}{l}\text { Before } \\
\text { activity }\end{array}$ & $\begin{array}{l}\text { After } \\
\text { activity }\end{array}$ & $\begin{array}{l}\text { Decrease } \\
\text { over base }\end{array}$ & $\begin{array}{l}\% \\
\text { reduction }\end{array}$ & $\begin{array}{l}\quad \text { 't' } \\
\text { Value } \\
*\end{array}$ \\
\hline Cutting & $\begin{array}{l}4.5 \\
\pm 2.18\end{array}$ & $\begin{array}{l}3.5 \\
\pm 1.32\end{array}$ & 1.0 & $\begin{array}{l}22.22 \\
\pm 3.33\end{array}$ & $7.14^{*}$ & $\begin{array}{l}5 \\
\pm 3.51\end{array}$ & $\begin{array}{l}3.5 \\
\pm 2.43\end{array}$ & 1.5 & $\begin{array}{l}30 \\
\pm 3.02\end{array}$ & $10.32^{*}$ \\
\hline Grating & $\begin{array}{l}4.5 \\
\pm 2.01\end{array}$ & $\begin{array}{l}2.5 \\
\pm 2.32\end{array}$ & 2.0 & $\begin{array}{l}44.15 \\
\pm 3.12\end{array}$ & $11.69^{*}$ & $\begin{array}{l}4 \\
\pm 1.27\end{array}$ & $\begin{array}{l}2.10 \\
\pm 3.67\end{array}$ & 1.90 & $\begin{array}{l}47.00 \\
\pm 4.87\end{array}$ & $15.75^{*}$ \\
\hline Kneading & $\begin{array}{l}3.5 \\
\pm 3.32\end{array}$ & $\begin{array}{l}2 \\
\pm 1.32\end{array}$ & 1.5 & $\begin{array}{l}42.85 \\
\pm 2.64\end{array}$ & $7.34 *$ & $\begin{array}{l}5.5 \\
\pm 1.05\end{array}$ & $\begin{array}{l}3 \\
\pm 2.01\end{array}$ & 2.5 & $\begin{array}{l}45.13 \\
\pm 3.51\end{array}$ & $7.48 *$ \\
\hline Rolling & $\begin{array}{l}4 \\
\pm 2.71\end{array}$ & $\begin{array}{l}3.5 \\
\pm 2.55\end{array}$ & 0.5 & $\begin{array}{l}12.5 \\
\pm 3.23\end{array}$ & $11.00 *$ & $\begin{array}{l}6.5 \\
\pm 1.32\end{array}$ & $\begin{array}{l}5.5 \\
\pm 1.78\end{array}$ & 1.0 & $\begin{array}{r}15.38 \\
\pm 5.57\end{array}$ & $12.74 *$ \\
\hline $\begin{array}{l}\text { Dish } \\
\text { washing }\end{array}$ & $\begin{array}{l}6 \\
\pm 2.52\end{array}$ & $\begin{array}{l}4.5 \\
\pm 3.72\end{array}$ & 1.5 & $\begin{array}{l}25 \\
\pm 3.81\end{array}$ & $6.72 *$ & $\begin{array}{l}6 \\
\pm 1.92\end{array}$ & $\begin{array}{l}4 \\
\pm 2.31\end{array}$ & 2.0 & $\begin{array}{l}33.33 \\
\pm 4.61\end{array}$ & $7.16^{*}$ \\
\hline
\end{tabular}

* Significant at $1 \%$ level of significance

3.4.2. Reduction in muscular pinch strength $(\mathrm{Kg})$ of selected subjects in doing selected activities

Data pertaining to the reduction in pinch strength after performing such activities where hands specifically fingers were involved is given in Table 2. The maximum percentage reduction in pinch strength of both the hands occurred while grating (44.15\% and $47.00 \%)$ for left and right hand respectively and minimum was after the performance of activity of rolling (12.50\% and $15.38 \%$ ) for left and right hand respectively. Kneading dough was another activity which could be considered as strenuous from this particular parameter point of view as data revealed that about $42.85 \%$ in left hand and $45.13 \%$ in right hand percentage reduction was observed.

Further the data also indicate that the percent decrease in pinch strength of right hand was more as compared to left hand. The paired t test values were 
found to be comparatively more significant for all activities for right hand (1\% level of significance). Similar results were reported by Maiti et al (2007)[4] who also found that there are significant differences between pinch strength of left hand and right hand as well as between male and female subjects.

\section{References}

[1] Armstrong C A and Oldham J A, A comparison of dominant and non-dominant hand strength. J Hand Surg, 24B(4), 1999 pp 421-425.

[2] Jindal U, A study of physical and temporal components of household work. Unpublished Ph.D Dissertation, Punjab Agricultural University, Ludhiana, India, 2000.

[3] Landan N and Stubler A, Ergonomic evaluation of homemakers while performing cooking activities. Ergonomics, 42 (1999), pp 503-509.

[4] Maiti D, De S, Harh M, Dhara C P, Age and sex related variation of pinch strength among adult bengalee population. In: Gite L P, Mehta C R, Kotwaliwale N and Majumdar J (ed) Developments in Agricultural and Industrial Ergonomics, Vol II. (2007) Pp 3-11. Allied Publishers Pvt. Ltd, New Delhi.

[5] Sandhu P, Malik M and Bakhshi R, 2008 Recommendations for selected household workstations for Punjabi(Indian) women. Proc. $9^{\text {th }}$ Southeast Asian Ergon. Conf.(SEAES 2008) pp 60. Bankok, Thailand.

[6] Verghese M A, Chatterjee L, Aterya N and Bhatnagar A, Rapid appraisal of occupational workload from a modified scale of perceived exertion. Ergonomics 37(1995) $485-491$.

[7] Verghese M A, Saha P N, Bhatnagar A and Narayane G G An acceptable workload for Indian workers. Ergonomics 22(1994) 1059-1071. 